SHORT REPORT

\title{
The feasibility and acceptability of collecting oral fluid from healthy children for anti-HCV testing
}

\author{
P Chatzipantazi, K M Roy, S O Cameron, D Goldberg, R Welbury, J Bagg
}

Arch Dis Child 2004;89:185-187. doi: 10.1136/adc.2003.031310

This pilot study investigated the feasibility of surveying, anonymously, HCV infection among healthy children using an oral fluid specimen. Seventy seven per cent of children provided their assent, or where appropriate, consent to participate; $2.8 \%$ were anti-HCV positive. Oral fluid collection is acceptable to children and more extensive studies are indicated.

$\mathrm{H}$ epatitis C virus (HCV) infection is a global public health problem affecting an estimated $3 \%$ of the world population; in Scotland, an estimated 35000 people, $0.7 \%$ of the population, are infected with HCV. ${ }^{1}$

Since the screening of blood for HCV was introduced in 1991, the predominant route of infection for children in the UK is mother to child transmission; the risk of transmission from an HCV antibody positive mother is estimated to be about $5 \% .^{2}$ The consequences of vertically acquired infection are not clearly understood. Given the asymptomatic nature of the infection, children with chronic disease may remain undiagnosed until the late appearance of symptoms in adolescence; late diagnosis precludes appropriate treatment and monitoring.

The limited information available reports the prevalence of HCV infection among apparently healthy children to be low, $0-0.4 \%$ in the Western world. $^{3{ }^{4}}$ To date, no prevalence studies of HCV among healthy children in the general population have been undertaken in the UK; this reflects, at least in part, the ethical issues of research involving children and, in particular, the inappropriateness of (or reluctance to perform) venepuncture if the child will derive no personal benefit. However, with the development of oral fluid collection devices, and the adaptation of commercially available anti-HCV tests for use on such fluids, ${ }^{5}$ the opportunity to apply these to children now exists.

Accordingly, the investigators undertook a pilot study to determine the feasibility, and acceptability, of using an oral fluid collection device to undertake an anonymous prevalence survey of anti-HCV infection among children.

\section{METHODS}

\section{Study setting and population}

A cross sectional survey involving the collection of nonidentifying epidemiological data and a saliva sample for voluntary anonymous anti-HCV testing was performed in the General Anaesthetic (GA) Department of the Glasgow Dental Hospital and School. The hospital serves the people of Glasgow and its surrounding areas. The setting was chosen because it was considered to be a non-intrusive environment in which to request an oral fluid sample and because Glasgow is known to have the highest prevalence of HCV in the UK and Europe.

\section{Sample size and eligibility}

In the context of what was a pilot study, the investigators aimed to recruit an arbitrary figure of 100 children. All children attending the GA Department between 14 and 24 June 2002 were asked to participate; children attending without a guardian were excluded.

\section{Consent and ethics}

Following an explanation of the study by a medically qualified researcher, written consent was sought from guardians. Assent from the children aged less than 7 years, and written consent from children aged 7 years and older, of consenting guardians was then sought. An information sheet for school age children was provided, while cartoons and play were used to describe the procedure to younger children (fig 1). If children refused to participate, verbally or nonverbally, no attempt was made to change their decision.

Ethical approval for the study was obtained from the Area Dental Ethics Committee, NHS Greater Glasgow.

\section{Data collection}

A standardised questionnaire was used to collect limited demographic information, including age, gender, and postcode sector of residence of the child. Risk information was not collected, although questions were asked of the guardians to determine whether they would be prepared to answer questions about, for example, injecting drug use behaviour.

\section{Oral fluid collection and anti-HCV testing}

Oral fluid specimens for anonymous anti-HCV testing were collected using the OraSure device (Altrix Healthcare plc, Warrington, UK). The collection of an oral fluid specimen has been shown to be of minimal risk to a child, ${ }^{6}$ and no adverse reactions to the collection device have been described.

Salivary anti-HCV was detected using the Murex anti-HCV 4.0 ELISA (Abbot Diagnostics, Maidenhead, UK), with the following modifications: the specimen volume was increased to $1 \mathrm{vol}$ of saliva $(100 \mu \mathrm{l})$ to $\mathrm{l} \mathrm{vol}$ of diluent $(100 \mu \mathrm{l})$, and the incubation period was increased to overnight $(\sim 20 \mathrm{~h})$ at room temperature; this assay has a sensitivity of $96 \%$ (personal communication, S Cameron). A positive salivary antibody test correlates well with serum HCV RNA status and is considered a good marker for hepatitis C viraemia in epidemiological studies. ${ }^{5}$

\section{RESULTS}

From a total of 91 guardians approached, 84 (92\%) consented to their child participating. Of the 84 children approached, 70 $(83.3 \%)$ assented and provided an oral fluid specimen. Ten children read the information sheet and signed the consent form. The overall participation rate was $77 \%$ (70/91; 95\% CI $68-86 \%)$. All guardians felt it was laudable that the child was directly involved in the decision to participate.

Table 1 presents the demographic characteristics of the study population. The sample was considered representative 


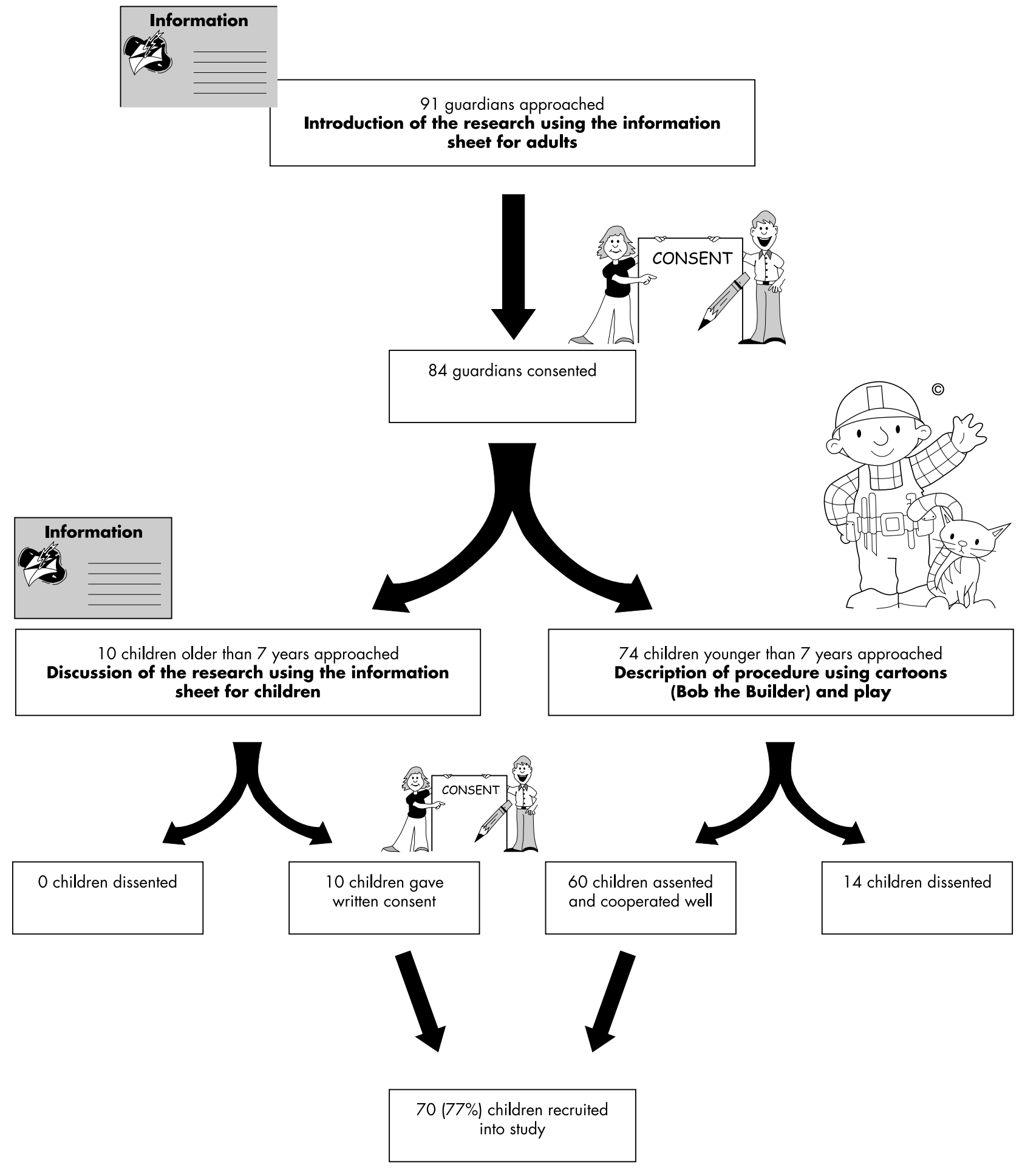

(C) HIT Entertainment PLC \& Keith Chapman 2002

Figure 1 Recruitment procedure for children attending GA Department, Glasgow Dental Hospital, between 16 and 24 June 2002.

of the child population attending the GA Department. The median age of the children who participated ( 5 years) was significantly greater than those who did not (95\% CI of the difference: $1-2$ years, $p=0.0027)$. Participation was not associated with gender or deprivation category. Although a number of children found the collection device distasteful, only one child terminated their participation by removing the device from their mouth. All guardians, except one, indicated that they would be comfortable answering questions about their own risk behaviours.

The prevalence of HCV infection among the sample was $2.9 \%(2 / 70$; $95 \%$ CI $0.35-9.9 \%)$.

\section{DISCUSSION}

Since the early 1990s, several epidemiological surveys of HIV and hepatitis virus infection among intravenous drug users in 
Table 1 Sociodemographic characteristics of the sample and the patient population receiving treatment in the GA Department over one year

\begin{tabular}{|c|c|c|}
\hline & $\begin{array}{l}\text { Sample } \\
n=91\end{array}$ & $\begin{array}{l}\text { GA paediatric } \\
\text { population* } \\
n=3500 \text { per year }\end{array}$ \\
\hline \multicolumn{3}{|l|}{ Age $(y) \dagger$} \\
\hline Median & 5 & 5 \\
\hline 25th-75th centile & $4-7$ & $4-7$ \\
\hline Range & $3-10$ & $3-14$ \\
\hline \multicolumn{3}{|l|}{ Gender } \\
\hline Males & $55 \%$ & $52 \%$ \\
\hline Females & $45 \%$ & $48 \%$ \\
\hline \multicolumn{3}{|l|}{ Parental deprivation category $\ddagger$} \\
\hline Deprivation category $1-4$ & $31 \%$ & $26.5 \%$ \\
\hline Deprivation category 5-7 & $69 \%$ & $73.5 \%$ \\
\hline
\end{tabular}

*Approximately 50\% of GA Department attenders are Glasgow City residents. The deprivation category distribution of this $50 \%$ is broadly representative of that for the city as a whole.

tThere was no exclusion criterion based on age; the absence of older children in the sample reflects an absence of older children attending the clinic during the recruitment period.

‡Carstairs scores for postcode sectors (1991) in Scotland. Seven

deprivation categories ranging from affluent (category 1) to deprived (category 7) localities.

the UK have used anonymous testing of oral fluid. This pilot study is the first attempt in the UK to use such a methodology to investigate the prevalence of HCV infection among a group of apparently healthy children, and showed that the voluntary collection of oral fluid specimens for anonymous HCV testing from children as young as 4 years is possible and acceptable to both the children and their parents. No conclusions can be drawn on the prevalence of anti-HCV among children in Glasgow, as the sample size of the pilot study was small.

In undertaking the study, the child's rights, Scottish Law, ethical principles, and paediatric guidelines for ethical conduct of research with children were considered ${ }^{67}$ The researchers were satisfied that: (1) the parents were happy with the adequacy of the consent procedures; and (2) the children were capable of providing their assent and, where appropriate, consent to their involvement. The investigators conclude that larger studies among children are feasible, and as the resultant prevalence indicates, necessary to determine HCV prevalence among young populations.

\section{ACKNOWLEDGEMENTS}

We are grateful to the participating children and their parents. We would like to thank the nursing and administrative staff of the Oral Surgery Clinic, Glasgow Dental Hospital and School for their assistance during the recruitment period, and Linda McDonald and Karen Wilson of the Regional Virus Laboratory, Gartnavel General Hospital.

\section{Authors' affiliations}

P Chatzipantazi, Department of Public Health, University of Glasgow, UK

K M Roy, D Goldberg, Scottish Centre for Infection and Environmental Health, Clifton House, Glasgow, UK

S O Cameron, West of Scotland, Regional Virus Laboratory, Glasgow, UK

R Welbury, J Bagg, Glasgow Dental Hospital and School, 378

Sauchiehall Street, Glasgow, UK

Correspondence to: Dr K M Roy, Blood Borne Viruses \& STI Unit, Scottish Centre for Infection and Environmental Health, Clifton House, Clifton Place, Glasgow G3 7LN, UK; Kirsty.Roy@scieh.csa.scot.nhs.uk

Accepted 2 May 2003

\section{REFERENCES}

1 Scottish Needs Assessment Programme. Hepatitis C. Glasgow: Office for Public Health in Scotland, 2000.

2 Thomas SL, Newell ML, Peckham CS, et al. A review of hepatitis C virus (HCV) vertical transmission: risks of transmission to infants born to mothers with and without HCV viraemia or human immunodeficiency virus infection. Int J Epidemiol 1998;27:108-17.

3 Alter MJ, Kruszon-Moran D, Nainan OV, et al. The prevalence of hepatitis C virus infection in the United States, 1988 through 1994. N Engl J Med 1999;341:556-62.

4 Dominguez A, Bruguera M, Vidal J, et al. Community based seroepidemiological survey of HCV infection in Catalonia, Spain. J Med Virol 2001;65:688-93.

5 Cameron SO, Wilson KS, Good T, et al. Detection of antibodies against hepatitis $C$ virus in saliva: a marker of viral replication. J Viral Hepat 1999;6:141-4

6 Mclntosh N, Bates P, Brykczynska G, et al. Guidelines for the ethical conduct of medical research involving children. Royal College of Paediatrics, Child Health: Ethics Advisory Committee. Arch Dis Child 2000;82:177-82.

7 BMA Medical Ethics Department. Consent, rights and choices in health care for children and young people. London: BMJ Publications, 2000. 